Journal of the British Association for Chinese Studies, Vol. 9 (1), January 2019 ISSN 2048-0601

(C) British Association for Chinese Studies

\title{
The Naturalisation of Motherhood Within Marriage and its Implications for Chinese Academic Women
}

\author{
Kailing Xie \\ University of Warwick
}

\begin{abstract}
As a result of the one-child policy implemented in 1979, daughters born into urban households have benefited from unprecedented educational investment due to the lack of competition from brothers (Fong, 2006). In recent years, a Confucian discourse of filial piety was adopted by the party-state to tackle population risks and counter individualism, which drew on "traditional" notions of gender and generational hierarchy to reinforce the heterosexual family as the main welfare provider (Zheng, 2018; Qi, 2014). The 1980s only-child generation raised under this ideology has now reached the age of marrying, child-raising and establishing a career. This paper investigates how gender affects the career and reproductive choices of China's well-educated daughters, particularly those working in academia. Drawing on a sub-set of a larger sample, I focus on data from interviews with eight women who currently work in Chinese universities and are at different life stages. I illustrate how, in spite of being at the top of the ivory tower, the gender stereotype that a woman's primary responsibility is towards her family poses a major obstacle to those who seek career progression. I analyse how the existing socio-political discourse constructs a naturalised female subject that is bound by reproductive norms, and the implication of this for women's careers.
\end{abstract}

Key words: China, academic women, motherhood, domestic labour, heterosexual marriage.

The success of China's economic reforms launched in 1978 has made China a world power and resulted in immense changes in Chinese society. The market economy has reduced poverty, but gender and income inequality have increased (Riskin, 2001; Wu, 2010). Though new possibilities of self-expression

I would like to thank the two anonymous reviewers for their detailed, constructive comments on this paper. 
have opened up, there has also been a backlash against the claims for gender equality associated with "gender sameness" based on the male standard promoted during Mao's China (Evans, 1997). Young women were actively encouraged to choose a career appropriate to "female capabilities", which led to male preference in job allocation in the 1980 s and pushed women to engage in work that is traditionally considered the purview of women (Honig \& Hershatter, 1988). As urban unemployment rose, women were called to return home in the 1990s (Evans, 1997). The commercialisation of female sexuality has become an ever-present phenomenon as the market economy prevails (Zurndorfer, 2016). Reports show the widening of the gender pay gap in various professions (Catalyst, 2016). As a result, many Chinese feminist scholars conclude that women's liberation has encountered serious setbacks in the era of economic reform (Wu, 2010; Wolf, 1985). Despite these changes, Chinese women's labour force participation remains relatively high-63\% compared to the world average of $49.49 \%$, although it has fallen $10 \%$ since the 1990 s (World Bank, 2016). While the market economy disadvantages older and less educated women in the labour market (Liu, 2008), this paper addresses the experience of the most educated women in the Chinese population, who grew up under the one-child policy.

The controversial "one-child policy" went hand-in-hand with marketisation, which was designed to facilitate economic growth by having "fewer but better quality" children. It has created a unique generation and fundamentally shaped the demographic landscape of contemporary Chinese society. While the policy led to a gender imbalance as a result of exacerbated son preference, an unexpected consequence was that the (vast) majority of urban girls born in this only-child generation have enjoyed unprecedented educational investment from their family due to the lack of competition from brothers (Tsui \& Rich, 2002). Their upbringing fostered a desire for personal success, as well as confidence in their career prospects (Xie, 2017).

The one-child policy marked a steady increase in women's participation in higher education, rising from around $30 \%$ for the pre-1980s birth cohort to nearly 50\% for the 1990-1992 cohort (Liu, 2016). Despite Chinese women's increasing representation in higher education and high labour force participation, gender discrimination is not new in the workforce, with rare 
female representation in senior positions (Zeng \& Thorneman, 2014). A national survey carried out in 2010 reveals that more than $72 \%$ of Chinese women had a clear perception of "not being hired or promoted because of gender" discrimination (Yang, 2012). Liu Jieyu (2016) illuminates how re-sexualisation of women sustains a heteronormative masculine organisational culture that marginalises women in white-collar professions, positions many university women graduates aspire to, contributing to the persistence of the gender pay gap. The World Economic Forum (2017) ranked China 100 out of 144 countries and territories in the Global Gender Gap Report in 2017, lagging behind of both the US (49) and Russia (71). The same report also noted a widening pay gap between the sexes for similar work. A recent survey done by China's major hiring website Zhaopin showed that women earn 22\% less than their male counterparts, on average, due to the cultural assumption that women are homemakers (Li, 2018).

Chinese Communist Party (CCP) policies have long assumed Chinese women's dual roles as worker and mother, but the latter has been heightened as primary in its recent policy moves, such as the two-child policy and its reemphasising of traditional family values substantiated by Confucian discourse (Hong-Fincher, 2018). In both popular and official discourse, the ideal woman is viewed as a "life support machine to a busy and successful husband" (McMillan 2006: 15), a view that the All China Women's Federation (ACWF) have endorsed (HongFincher, 2012). As the national body formally responsible for women's affairs, the ACWF, like other state institutions, has served as a "transmission belt" between the Party and society. With its cadres appointed and paid by the partystate, it often faces a recurrent dilemma of reconciling the often incompatible goals to serve the interests of the Party and those of its members with a topdown approach to subordinate gender issues to the priorities of the Party (Howell, 1996). The party-state has ensured the monopoly of representation of women's interests through ACWF by using regulations that restrict the operation of "similar" independent organisations, as reflected in the recent change of laws that practically made foreign women's and LGBT rights NGOs unable to function within China (Saich, 2000; Hancock, 2018). The close ties between the party-state's agenda and the ACWF's position is also reflected in a speech given by President Xi to the new leaders of the ACWF in 2018, where he points out that family work and utilising the "unique function" of Chinese 
women in family and society should be the main focus of ACWF's service to the "bigger picture" and women (Xinhua wang, 2018). The speech states that the "ACWF should lead women to love both the small private family but also the big national family [...] encourage them to utilise their advantages to facilitate family harmony, the healthy upbringing of children, caring for the elders, as well as managing the relationship between work and family well, in order to contribute to both society and the family" (Xinhua wang, 2018). It becomes apparent that the current state vision for Chinese women is contributing to society through her "unique" service to the family.

Against this backdrop, this paper focuses on the experience of eight highly educated women at different life and marital stages, who currently work in Chinese academia. Although my small sample only offers indicative, not representative findings, it illuminates the continuing restrictive influences arising from the naturalisation of motherhood within marriage upheld by the official discourse on women's career progression. By offering empirical evidence based on these privileged women's experiences when facing this structural constraint, it argues against the common assumption that gender equality follows the economic growth and educational enhancement extolled by the Chinese state and the ACWF (Xinhua wang, 2014). I begin by describing the study from which the data is drawn.

\section{Methodology}

This article draws on data gathered in a larger study that looks more broadly at the gendered lives of China's privileged daughters: well-educated women from urban China born in the 1980s' only-child generation. In particular, it explores how these well-educated heterosexual women experience their gendered adulthood, and employ varying strategies to negotiate and rework the notion of being (good) Chinese women. Adopting a feminist approach, this research used in-depth interviews to uncover the experiences of women facing the structural oppression mutually sustained by a hybrid of capitalism and patriarchy distinct to the Chinese context (Rubin \& Rubin, 2012). I initially interviewed 33 women and 12 men in 2015, and subsequently added four women academics in 2017. All of my participants were university-educated, with a four-year bachelor's 
degree at a minimum. They were all in full-time employment in various whitecollar professions, such as schoolteachers, bank managers, government employees, and office staff in private firms, with some variation in their incomes.

I applied a thematic and narrative analysis with the intention of looking at constructions of femininities among these women, while also paying attention to distinct cases. In the following sections, I primarily examine the accounts of eight academic women (see table 1), ${ }^{1}$ because they appeared indicative of Chinese women's experiences at the top of the ivory tower, despite facing the same normalised life course as the rest of the cohort. They were also selected because they offered more nuanced accounts of the experience of academic women at a time when popular wisdom and official discourse suggested that gender equality followed higher levels of education.

To understand the rationale behind their career choice, I included questions exploring their ambitions and family expectations, as well as childcare arrangements when applicable. Vignettes, "mini-narratives or scenarios, usually centred on a problem or dilemma facing an imaginary protagonist, designed to elicit responses on what a person would or should do in the situation depicted" (Jackson et al., 2016: 37), were used to probe participants' opinions on topics around sex and reproduction, which are still relatively sensitive topics even among close friends. One of these vignettes, which I call the "DINK vignette", 2 is particularly relevant for this paper:

Luqi (a woman) has been married for two years. The couple have been busy at work, thus do not want children. However, both of their parents urge them to do so. What do you think?

\footnotetext{
${ }^{1}$ Despite being born before the One Child Policy, Tong's experience is included to highlight the tension Chinese academic women face today.

${ }^{2}$ DINK refers "Double Income No Kids". In this context, it connotes a married couple, who are biologically able and financially capable.
} 


\begin{tabular}{|c|c|c|c|c|c|}
\hline Name & $\begin{array}{l}\text { Highest } \\
\text { degree } \\
\text { obtained }\end{array}$ & $\begin{array}{l}\text { Marital } \\
\text { status }\end{array}$ & $\begin{array}{l}\text { Professional } \\
\text { title }\end{array}$ & Age & Discipline \\
\hline Gingko & PhD & $\begin{array}{l}\text { Married } \\
\text { with young } \\
\text { baby }\end{array}$ & $\begin{array}{l}\text { Junior } \\
\text { researcher }\end{array}$ & 29 & $\begin{array}{l}\text { Environmental } \\
\text { Science }\end{array}$ \\
\hline Jo & PhD & Single & \begin{tabular}{|l} 
Junior \\
researcher
\end{tabular} & 28 & Social Science \\
\hline Linda & $\mathrm{PhD}$ & $\begin{array}{l}\text { In a stable } \\
\text { relationship }\end{array}$ & \begin{tabular}{|l|} 
Junior \\
researcher
\end{tabular} & 29 & Humanities \\
\hline Lulu & MSc & $\begin{array}{l}\text { Divorced } \\
\text { with a five- } \\
\text { year-old } \\
\text { daughter }\end{array}$ & $\begin{array}{l}\text { Lecturer and } \\
\text { leader of a } \\
\text { research lab }\end{array}$ & 32 & $\begin{array}{l}\text { Computer } \\
\text { Science }\end{array}$ \\
\hline Muyu & MSc & Single & \begin{tabular}{|l} 
Junior \\
researcher
\end{tabular} & 27 & Medical Science \\
\hline Tong & $\mathrm{PhD}$ & Single & Lecturer & 45 & \begin{tabular}{|l|} 
Environmental \\
Science
\end{tabular} \\
\hline Xiu & PhD & Single & $\begin{array}{l}\text { Junior } \\
\text { researcher }\end{array}$ & 31 & $\begin{array}{l}\text { Environmental } \\
\text { Science }\end{array}$ \\
\hline Yuhan & $\mathrm{PhD}$ & $\begin{array}{l}\text { Married } \\
\text { with two } \\
\text { children }\end{array}$ & Lecturer & 35 & Design \\
\hline
\end{tabular}

Table 1: List of female academics. 
The vignette was deliberately phrased in a way that does not assume only women face the pressure to have children within marriage; therefore, it leaves space for my participants to interpret it according to their experiences. Responses to the vignette have revealed a unanimous assumption that it is a women's problem. It is her body, and decisions in this scenario fall under close scrutiny in Chinese society, as will be discussed below.

\section{The Necessity of Marriage}

The universality of heterosexual monogamous marriage permeates the psyche of Chinese people, such that marriage is not been a choice but an obligation (Evans, 2002; McMillan, 2006). The 1950 Marriage Law first enshrined freechoice monogamous marriage under the CCP's rule as the central pillar of its explicit goal of gender equality. Despite its revolutionary nature, Evans (2007) points out the law still was premised on a naturalised and hierarchical view of gender relations, where a woman's obligation within monogamy was to serve her husband's interests and needs. A brief historical review shows that heterosexual marriage in China had not been a matter of private enjoyment but was supposed to serve the interests of society as a whole (Mann, 2011; Evans, 1997). From giving explicit advice to young people about marriage and love in the 1950s, to giving nearly no advice on such topics in during the Cultural Revolution, the state's interventions have aimed to ensure that the youth have a correct sexual morality and attitude that fits into the political priorities of the time. The AWFC has sponsored much of the discussion concerning women's social and economic status, according to the Party line of the time (Evans, 1997). Even encouraging individuals to master sexual knowledge for sexual satisfaction in the reform era is backed by state's concern with promoting modernisation and social stability by avoiding family breakdown (Wong, 2016). The intimacy of state power in China has long preyed upon marriage as a powerful institution linking personal desires with state goals, premised on the forging of female subjects committed to its designed ideals (Friedman, 2005).

Meanwhile, there has been a demographic alarm unveiled by the 2010 national census data, which suggests that $24.7 \%$ of Chinese men above the age of 15 have never been married, comparing to $18.5 \%$ of unwed women in the 
same age group (PRC Population Bureau, 2010). Son preference exacerbated by the one-child policy has contributed to this figure, which left 20 million more men than women (Peng, 2011). Following the norm that men marry down and women marry up, large numbers of social and economically marginalised men struggle to find wives. These involuntary bachelors, unable to bear fruits for their family tree, and often referred to as "bare branches" (guanggun 管棍), have added to the Chinese state's concern for social stability (Li, 2017). Both popular lore and conventional evolutionary thinking suggest that more males lead to more violence (Hudson \& den Boer, 2004), and Chinese history also provides ample evidence of social stability being threatened by social and economically marginalised "bare branches" (Mann, 2011). Combined with a rapidly aging population and a low birth rate, the dire demographic trend poses particular threats to the economic growth and political stability that is at the heart of the CCP's concern (Wang, 2010). Consequently, the state has shown keen interest in relying on women's reproductive labour to mitigate these social risks (Hong-Fincher, 2018). Switching to the two-child policy in 2016, and implicitly pressuring educated women to marry through its propaganda machine, including the AWFC, are just two indicators' of the state's intentions (Hong-Fincher, 2012).

The marriage dilemma of high-achieving women, and their stigmatisation, are not news in China, despite the skewed gender ratio (Journeyman, 2012; Poston \& Glover, 2005; Hong-Fincher, 2014). To (2013) argues that the persistence of the Chinese patriarchal structure is the leading cause of this phenomenon. It is the consensus among my participants that the desirability of a woman is tied to her youth, whereas men's seniority in age adds merit to his attractiveness ${ }^{3}$. "It is extremely difficult for a woman to find a spouse after a certain age [...], no matter how good she is in other aspects" (Namei). The ACWF has been found complicit, attributing these women's marriage problems simply to them "having unrealistic demands" or "amoral sexual behavior" (Hong-Fincher, 2012). The close ties between the ACWF and the state suggests there has been a "propaganda push" directed at these unmarried women, which explains their tolerance if not direct endorsement of patriarchal attitudes. Marriage pressure

\footnotetext{
${ }^{3}$ Due to this view, men can dedicate more time to building up their careers, and face less time pressure to marry.
} 
is an ever present issue keenly felt by Chinese youth. As Hershatter (1984: 238) put it, because of the assumption that "everyone will marry, finding the proper spouse is a major concern of young people in their early and mid-twenties." Thirty years down the line, marriage remains a thorny issue among my participants, particularly because it is also closely tied to the reproductive norms regulated by the state.

\section{Safeguarding Reproduction}

Xie's study on Chinese women's attitudes towards premarital abortion reveals that marriage remains the only "right" place for childrearing, and single motherhood is frowned upon and practically difficult (Xie, 2018). McMillan (2006: 69) notes that reproduction is naturalised for Chinese women as "a psychological instinct, at least in women, and having a child is almost as much an inevitability of the female body as dying". When shown the DINK vignette, many indicated some difficulty in fully comprehending voluntary childlessness within marriage. Childlessness in this case is often interpreted as a mistake for the woman. "She will surely regret it when she gets older" (Lulu). Therefore, marriage is a necessity, if childbirth is anticipated.

In addition, eugenic practices have been long rooted in China's population planning policies (Greenhalgh \& Winckler, 2005). A generic Baidu (Chinese search engine) search “zui jia shengyu nianling" (最佳生育年龄; the best time to give birth) will bring you much "expert" advice, claiming that "scientifically speaking" the best time to reproduce is between the ages of "23-30" for women and "30-35" for men, ensuring the quality of the egg and sperm in order to avoid genetic diseases and abnormality. With barely existing public support, and widespread social prejudice against disabilities, Chinese families are easily persuaded about the benefits of eugenic practices. However, men are rarely the focus of public scrutiny. Preserving women's fertility and reproductive capacity has been central to the discussion around reproductive health-a view that has been consistent since the beginning of the CCP's rule (Evans, 1997). My participants confirm the wide reception of such messages, agreeing that "it is best to give birth before 30, and after 35 would be too risky" (Lulu). If social reproductive norms compel women to marry, widespread eugenic beliefs 
impose a rather rigid timeframe on highly-educated women. It creates a kind of panic, in which one is "running to meet a deadline", as I indicate in the following diagram, based on my participants' accounts (see figure 1 below):

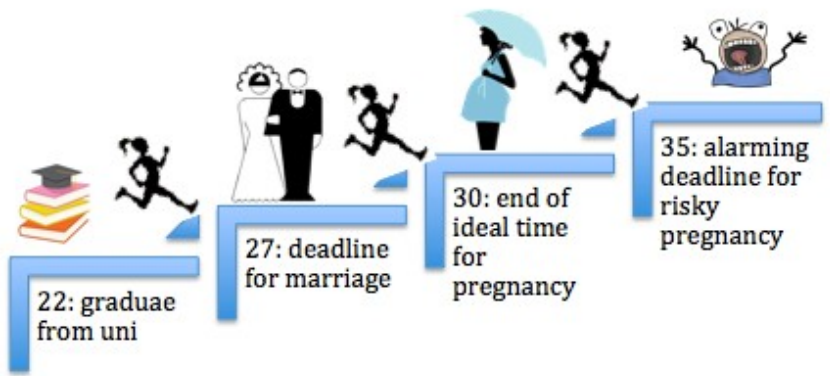

Figure 1. Running after the deadline(s) for university-educated Chinese women. Created by the author using clip-art and based on data collected.

It is worth noting that the prohibition on dating during school years is commonly inculcated by both teachers and parents (Farrer, 2006), although from 2005, university students were finally allowed to marry without facing the danger of dismissal (Farrer, 2006). Dating was still semi-secret in universities for my participants. Typically, Chinese students finish their undergraduate degree at the age of 22. Then, young women have five years to secure a career and pin down a husband before they are labelled as leftover women at the age of 27 . If they have managed to be married by then, they have three years in which to give birth, at least to the first child under the current two-child policy. For women pursuing an academic career, their timeframe is further tightened, as the master's degree usually takes three years, and it is common to take over four years to complete one's PhD depending on the individual's achievement of the publication quota. ${ }^{4}$ The average time to finish a PhD in China reported by my participants is about 5-6 years. Their prolonged education does not exempt them from facing social "deadlines". As Gingko says, "you can afford a break in work. If you decide not to have children because you are busy, how about if your body doesn't allow it?" Reproductive concerns remain central to their

\footnotetext{
${ }^{4}$ It is set as a requirement for Chinese PhD students to have at least one or two publications in key journals to apply for graduation. The exact number varies at each university.
} 
envisioned future, which exacerbates the time pressure women academics experience.

\section{The Pressure to Succeed}

Despite their career and academic achievements, without a married family life, women are unlikely to be viewed as "truly" successful by society. Tong gained her PhD in Germany, and now works in a top-ranking university in China. Single at 45, she shares her insight on how Chinese women's success is commonly measured:

In universities, most people measure success by professional title, project grants, award, and income; what kind of car you drive and how big your house is. Though it is more hidden, people still judge you based on material things. Furthermore, for women, there are additional criteria: what kind of man you marry and how well your kids are doing. [...] Because I am not married, and I do not have children, half of a woman's success is unrelated to me. [Quiet laugh.]

When probed on her response to this view, Tong rejects it by stating she has diverse values and does not apply a single rule to herself. Nevertheless, she admits the many practical difficulties of living as a single woman in China: "it is not easy. For a long time, you need to face your emotional struggle and selfdoubts. Plus, you need to deal with social pressure including malicious gossips and various speculations. Loneliness, social isolation, and safety concerns etc., you need to face all these on your own." Tong's narrative reveals the central role the heterosexual family plays in living a successful Chinese life, from organising an individual's social space, to providing reliable welfare and social recognition. All directly affect one's well-being.

The state's efforts at inculcating a belief in heterosexual marriage for personal happiness have had an effect, as all of my participants believed that having a happily married family is the most socially desirable life trajectory for women, despite many struggling to fulfil it. Becoming a mother, as described by Muyu 
and Namei, is a "must" for women-a crucial life experience if one is to "feel complete". Paradoxically, the popular image of a "sacrificial" good mother further romanticises motherhood as self-fulfilling, which coincides with the selfdetermination commonly shared among young women, to "experience it all, otherwise you are somehow lacking". However, married women with children often expressed ambiguity regarding such fulfilment, which suggests that these attitudes may shift with women's experience.

\section{Choice of Working in Academia}

Many note that commercialised femininities in the post-Mao era have transformed many women into glorious housewives, whose very existence marks their men's social status (Zurndorfer, 2016; Evans, 2000; Hooper, 1998). Despite a revitalisation of traditional gender values that attach women to the private sphere (Sun \& Chen, 2015), my participants' perception of work as an integral part of living a meaningful life remains strong, which might be explained by their urban upbringing and university education, which shaped their outlook. While most of their mothers have worked in the socialist danwei (单位; work unit), all my participants reject the idea of being a full-time housewife, and view unemployment almost as a personal failure. "I will NEVER be a fulltime housewife! [...] Although I am career-oriented, family life is also very important. [...] I also think that a woman without her own career, but just family, is [...] not very secure. [Laughter.] Also, her life seems to be lacking direction, in the realisation of her value" (Muyu). Regardless of marital status, they were all

employed full-time in different white-collar professions including university lecturers, which is a privileged identity-marker in the country's new middle class.

However, it would be a mistake to assume my participants would prioritise career ambitions over family life. On the contrary, work is commonlyperceived as an important element for enhancing "marital harmony". Women commonly worry that "without a public role in society to keep up knowledge exchange", it will make them "lag behind" and become "disconnected" from their husbands "if only he is progressing" (Gingko). Such a view, widely shared by women I interviewed, reflects their careful strategizing when facing the rising possibility of divorce in China (Zhou, 2017). Importantly, most middle-class men these 
women marry cannot afford a stay-at-home wife, which makes a double income a necessity for maintaining the family's standard of living in China's materialistic culture (Croll, 2006). Women are fully aware of the requirements of keeping oneself desirable both in intimate relationships and in the market economy, and for stabilising their gendered position in the respectable middle-class.

Maintaining a good marriage remains the major concern for my participants when making decisions about work. There remains an internalised sense of domestic duty, so their work should adapt to domestic needs. Contemplating the possibility of being a housewife, Gingko jokes: "Only if he becomes president, and it is no longer suitable for me to go out in public [pao tou lu mian 抛头露 面]! [Laugh.] But I don't think he will! [...] If I must become one, I will consider it." This reveals the traditional elite gender ideal: men leading the outer domain and women leading the inner domain. Though told as a joke, it shows that Gingko still privileges her husband's work, and if that required her to give up her own work, she would. Similar thoughts were shared by many of those I interviewed.

Therefore, the role of men as the main symbolic breadwinner is kept intact both in discourse and in practice among my participants. A women's job should give her stability and the flexibility to look after her family. For instance, Liu's parents' want her to work as "a civil servant or teacher, no other big expectations", because "stability is good for girls", whereas their "family business is not suitable as it is too much hard work for girls" despite it entailing a much higher income. Gingko's accounts of her husband's career decisions reveal similar gendered choices about professions:

Most boys I know would choose to work [outside academia]. [...] They prefer to start earning early. Like my husband, he thinks that a man's responsibility is to earn a living. Men should not always hide in the "ivory tower" [...] and studying does not guarantee you a golden house [huangjin $w u$ 黃金屋]. [...] Many mothers-in-law now ask for the men to provide the marital home; maybe women don't have such financial pressure, so they can choose to study further. 
University here is perceived as a shelter from the "real world", whereas men should go out to embrace more risk and financial reward.

Chinese universities have only just started (since 2016) to widely implement contracts of employment instead of a lifetime guarantee (Huang \& Xin, 2016). Compared to other private companies, most Chinese universities are still publicly-funded, and a lectureship does not require staying in the office from nine to five, which provides better flexibility and stability for women with domestic responsibilities. For this reason, Yuhan's husband pushed her to complete a PhD, because he thinks it would give her more time to take care of their two children. In addition, women working in education are widely believed to be better equipped to raise "quality children". Higher education also symbolises class-privilege in a culture that traditionally values education as the primary path of upward social mobility (Chen \& Uttal, 1988). Consequently, it has become a suitable profession for well-educated women supported by their families, despite its modest income, ${ }^{5}$ enabling them to "have it all". Examining the experience of women academics soon reveals a different reality.

\section{Naturalised Female Gender}

One obvious paradox I observed among these women is that on the one hand, equality between men and women is widely accepted as if it is the norm, thanks to the party-state's rhetorical claims about equality. Yet the party-state's long history of using "scientific knowledge about sex" to regulate people's sexual conduct according to its moral and social boundaries means there has been a tendency to legitimise the subordination of women as a natural condition rooted in heterosexual assumptions. As Evans (2007: 54) states, despite an increasing focus on psychology and culture, and society's influence on sexual difference in recent years, "continuing adherence to the biological construction of sexuality severely restricts conceptual, as well as political, possibilities of

\footnotetext{
${ }^{5}$ There is wide disparity among individual incomes in higher education, depending on variables like professional rank, discipline and success in research projects. In general, the maledominated fields of science and engineering earn more than the more female disciplines of the humanities and social sciences. For more discussion, see Zhihu(2013).
} 
change in gender relations". This paradox often led women, like Muyu, to justify and accept gender inequality as a natural condition:

I don't think there should be a fixed responsibility within the family. To make a family work, efforts have to come from both sides. However, to raise emotionally healthy children, women should contribute more. [...] Objectively speaking, it is to do with the biological differences between men and women. Women are much more sensitive and softer, which is very helpful when communicating with children, and taking good care of them.

The dominant construction of gender distinctions is built on a naturalised link between female sexuality and their reproductive role (Evens, 2007), which severely constrains Chinese women's agency to navigate competing demands as worker and mother. Whilst childbirth reinforces women's domestic roles, becoming a father boosts Chinese men's symbolic responsibility as the main breadwinner. Men's commitment to long working hours is often read as selfsacrifice to serve the needs of the family (Yang et al., 2000). Consequently, he is excused from many family chores so he can pursue his career. The gendered division of labour between couples becomes increasingly identifiable after childbirth. Despite the fact that Yuhan and her husband both gained PhDs and work in Chinese universities as lecturers, he left childcare completely to Yuhan, who describes it as “widowed education" (sang'ou shi jiaoyu 丧偶式教育). She explains: "This popular Chinese term basically means only mothers are present while kids are growing up! It is like their dad is dead! [Laughter.]" Since her husband is dedicated to building his research career, Yuhan's mom is her main helper. This childcare arrangement represents a common pattern shared among my participants, in which family elders' support with childcare and housework is crucial in helping Chinese working mothers to juggle between work and family (Chen et al., 2011).

Although some research indicates that Chinese fathers have become more involved in childcare (Li \& Lamb, 2013), in my sample, the husband's occasional involvement with children is still viewed as exceptional and far from the norm: "If one dad accompanies his child to some extracurricular activities among my 
friendship circle, he will surely be highly praised!" (Yuhan). Like their American counterparts in the 1980s (Hochschild, 1989), men also have more freedom to choose tasks according to their preference, whereas women are more likely to take up routine and undesirable house chores. "Dad can only play with the baby a bit after work [...] so the rest is all me!"(Gingko).

\section{Gender Discrimination at Work}

The party-state has never completely forgone the domestic role of women as mothers; instead, it has naturalised gender differences with "scientific truth". So, women's participation in the labour force alone has failed to deliver gender equality. Robinson (1985) argues that social and economic policies since the start of the reforms have created conditions which are imposing sexdifferentiated roles on women (and men) in production and reproduction, and which sustain the traditional definition of women as reproductive labourers. Despite the perceived suitability for women of working in the education sector, the reality of securing a permanent academic position has proved to be increasingly difficult. The growing casualisation and intensification of academic labour following market rules has increased the demand on research output for career progression (Li \& Liu, 2015). In this regard, Chinese academia resembles what the Res-Sisters (2017: 268) observed in contemporary British academia, where a particular type of subject: "enterprising, highly productive, competitive, always available, and able to withstand pre-carity" is favoured. Within this structure, individuals, often men, without domestic responsibilities, have competitive advantages. The increasing demand of economic efficiency following market logic means that Chinese women's subordination in the workplace has become ever more apparent, and academia is no exception.

Although gender discrimination in employment is technically illegal in China, ${ }^{6}$ the lack of practical safeguarding measures means that women constantly face overt discriminatory practices. Employers, whose primary concern is with efficiency and minimising cost, consider women incapable of devoting themselves to jobs as fully as men do. Practices of male preference from

\footnotetext{
${ }^{6}$ See more details in the Law of the People's Republic of China on the Protection of Women's Rights and Interests, Labour law and Employment Promotion Act.
} 
recruitment to promotion are widespread. Women have to demonstrate excellence while competing for the same job with men who only need to meet the basic requirements. As Namei observes: "Discrimination is for sure. At the same level, if girls are slightly better than boys, it must be the boy that got the job!"

Unlike in the UK and US, where interviewers are legally not entitled to ask questions about marital and childbearing status, probing questions around the age of women, their marital status and their children during recruitment are commonplace in China, said my other participants working in HR. Employers who do not want to assume the cost of women's maternity leave can reject her upfront, as Gingko experienced: "They heard I am pregnant, so rejected me directly, because 'the job requires fieldwork in the wild.'" Young women who check the box "already married with children" (yihun yiyun 已婚已孕) stand a higher chance than their peers who have yet to do so. Fully aware of this prevailing discrimination, women often choose to self-declare if they are married with children to increase their chances.

In order to secure their job prospects, women often commonly make extra sacrifices to show their worth. Facing increasing demands from work, Tong had a breakdown in 2013 because of overwork, which she acknowledges is a common practice in her university. In order to avoid leaving a bad mark with her boss, Lulu terminated her first pregnancy. As a new employee, the timing of Lulu's pregnancy was "problematic". She believes going on maternity leave too early would risk her career prospects, establishing her as a "stereotypical woman" who prioritised family over work. In China's relational society, unspoken rules matter: she needs to carefully consider the implications of her pregnancy at multiple levels: her age, career plan and family expectations. Similarly, Muyu's colleague became pregnant while doing a research project, but she decided to keep the baby: "Our boss was not happy. He moved her to a featherbed post. Though it is good for her to care for her kids. But objectively speaking, her research career is finished." Expecting increased maternal responsibilities under the two-child policy, and aware of the rudimentary legal protections in a workplace prioritising economic efficiency, Muyu laments: "I am at the age to get married and have children. Then it would be difficult for 
my career to develop. [...] It seems really hard to change! It is impossible to ask your danwei (work unit) to change for you!"

The official maternity leave was 98 days at the time of the interview, ${ }^{7}$ which is substantially longer than the much shorter, unestablished paternity leave (Encyclopedia, 2017). In order to keep their job prospects in a male-privileged workplace, many women cut their maternity leave short-like Gingko, who returned to her post-doc within one month of childbirth: "This child turned me into a superwoman. I have to keep working, though desperate for some sleep, and it is 365 non-stop." But for many women, "various family duties make it impossible for academic women to be free to take up workloads that can increase their promotion chances" (Tong), which reinforces the impression that women are simply uncommitted to work like Muyu's boss believes: "for him, it is a waste of the department's resources to invest in women [...] so he prefers men".

Gradually, and unsurprisingly, vertical gender segregation comes about, as shown by the example of Yuhan and her husband. They started as lecturers in the same discipline; the criteria for career progression applied equally to both. However, due to her family responsibilities, she fell far behind her husband: "He is now an associate professor and has his own research team. I am still just a 'small' lecturer". Lacking publications, Yuhan is unable to move to a better university where her family lives. She has to commute every week between two cities, juggling the double demands of being a mother of two, and a lecturer. It also means she is on a contract instead of holding a permanent post in the university. It bears a resemblance to what Reay (2014) noted as the gendered nature of the casualisation of academic labour in the UK, where women are disproportionally found in subordinate positions serving those who generate academic capital, overwhelmingly men. With frustration, Yuhan asks: "Why can't men take paternity leave? Only then will he know what it is like after he returns to work when his position is replaced by others, and promotion has vanished."

\footnotetext{
${ }^{7}$ There was a slight increase when the two-child policy started in 2016.
} 


\section{An Ongoing Battle}

The marginalisation of women in Chinese academia revealed above has been consistent with previous findings on Chinese women's work experience elsewhere, due to their naturalised reproductive duty, which has been upheld by the party-state's official discourse since the beginning of its rule (Evans, 1997; Hershatter, 1984; Wolf, 1985). Meanwhile, my data reveals that women are commonly perceived as the weaker sex due to an essentialist discourse; therefore, they are unsuitable for certain tasks, including going on work trips. Moreover, a largely male-dominated business culture that frequently consumes female sexuality to facilitate deals means that women need to tread a fine moral line if they are to forge ahead (Zurndorfer, 2016; Liu, 2008). Similar issues are commonly faced by both women academics and the white-collar women I interviewed. Consequently, on both symbolic and practical levels, the upward and outward mobility of women into the world of men is constrained. It also shows that access to education alone does not lead to gender equality for women, with further complications brought about by the two-child policy.

As the current pressure on women's reproductive labour rises, so do the demands of gender equality among young people. China has given birth to large numbers of well-educated women. These young women form a solid base for its burgeoning young feminist movement (Hong-Fincher, 2018). As Wolf (1985) proposed: "[Chinese] women must make their own revolution", since the revolution promised to Chinese women from the state has under-delivered. However, the party-state has shown a strong intention to hold onto the family as the foundation of society by reinforcing traditional family values, with institutions including the ACWF and the CCP Youth League coming to its aid. Despite the pressure of conformity when living in China's patriarchal authoritarian society, using Hong-Fincher's term (2018), the reality is that many young women have devoted considerable amounts of time to developing their careers, like Xiu, and have refused to compromise, but will only marry for love, as my participants confided to me. Women I have interviewed have started to pursue different ways of life outside of conventional marriage, willingly or not. Maybe a silent resistance is underway, as the recent marriage and divorce rate indicates (Zhou, 2017). 
Linda, an ambitious young researcher, comments on the way forward: "'Gender equality' is written on paper; we should take full advantage of this official rhetoric and participate in paid employment, entering places of influence and power like politics, the media and academia." Despite facing major obstacles, talented women are entering academia, as Tong observed: "I do respect those capable and talented women, despite being labelled as a 'third gender' or as 'female strong men'. They do not let their talent go wasted." I hope that, nevertheless, Chinese academic women will persist.

\section{Conclusion}

Since family-based heterosexual marriage remains a basic governing site for social stability (Sigley, 2001), women's reproductive choices carry political significance, which makes them a target of the state's policing. Therefore, their gendered subjectivity combines pressure from cultural and biomedical discourses on women's marriage and childbirth upheld by the party-state. Their education, and China's socialist past, on the other hand, have normalised their desire to participate in public life. Consequently, these women's lives embody multiple contradictory state policies from the past and present. They become tension-bearers for the reconciliation of the conflicting demands of the partystate on individuals, and on women in particular. Regulating women's personal decisions around marriage and reproduction becomes the key to solving problems faced by the party-state, including declining birth rates, an aging population and social risks posed by large number of surplus men. Facing a powerful state with an increased interest in harnessing women's reproductive labour to stabilise its contemporary governance, women constantly face battles against discriminatory practices both in the marriage and job markets. The essentialist discourse on gender and sexuality, upheld by the official discourse, bind women to their naturalised gender positions, and further obscure the gender oppression experienced by women with a public claim to equality.

By exploring the lives of privileged women, who are at the top of the ivory tower, gender inequality is thrown into sharp relief. It contradicts the popular belief that education and economic development lead to gender equality. On the contrary, the naturalisation of motherhood within heterosexual marriage 
means that women are hugely weighed down by their domestic responsibilities, which restricts their career progression. With work remaining an important identity marker, well-educated women need to master precise time management practices and astute resource deployment skills. Academia, a career deemed suitable for well-educated Chinese women, instead of enabling them to "have it all", becomes another place that mirrors the dominance of men in Chinese society more broadly.

In 2018, a report showed that 1.8 times more men are taking doctorate degrees, with an entrenched gender divide according to discipline, with 1.6 times more women in education than men versus 2.3 times more men in engineering (Sohu News, 2018). Detailed analysis of women's experience based on disciplines is beyond the scope of this research, and the cases presented above only offer indicative, not representative, findings regarding the experience of Chinese women working in academia. The issues presented in this article do reveal the major obstacles widely faced by well-educated women in Chinese society, which raise serious questions about women's liberation within the current official framework, and the desperate need for autonomous women's organisations to exist. It also resonates with many of the contradictions women face under transformed patriarchy regimes combined with capitalism around the globe, where an emphasis on economic efficiency and privatisation has often left women bearing the burden of public costs made private.

\section{References}

Catalyst (2016), "Women in the Workforce: China", July 8, available at: http://www.catalyst.org/knowledge/women-workforce-china (accessed 01. 08.2017).

Chen, Feinian, Guangya Liu and Christine A. Mair (2011), "Intergenerational Ties in Context: Grandparents Caring for Grandchildren in China", Social Forces 90(2): 571-594.

Chen, Chuansheng and David H. Uttal (1988), "Cultural Values, Parents' Beliefs, and Children's Achievement in the United States and China", Human Development 31(6): 351-358. 
Croll, Elisabeth (2006), China's New Consumers: Social Development and Domestic Demand, London: Routledge.

Encyclopedia of Maternity Leave (2017), available at: http://baike.pcbaby.com. $\mathrm{cn} / \mathrm{qzbd} / 1269632 . \mathrm{html}$ (accessed 08.08.2017).

Evans, Harriet (1997), Women and Sexuality in China: Dominant Discourses of Female Sexuality and Gender Since 1949, Cambridge: Policy Press.

-- (2000), "Marketing Femininity: Images of the Modern Chinese Woman", 217-244, in L.M. Jensen and T.B. Weston (eds.), China Beyond the Headlines, Lanham, MD: Rowman and Littlefield.

- - (2002), "Past, Perfect or Imperfect: Changing Images of the Ideal Wife", 335-360, in Susan Brownell and Jeffrey N. Wasserstrom (eds.), Chinese Femininities/Chinese Masculinities: A Reader, Berkeley: University of California Press.

Farrer, James (2006), "Sexual Citizenship and the Politics of Sexual Storytelling Among Chinese Youth", 102-123, in Elaine Jeffreys (ed.), Sex and Sexuality in China, London: Routledge.

Fong, Vanessa L. (2006), Only Hope: Coming of Age Under China's One-Child Policy, Stanford: Stanford University Press.

Friedman, S. L. (2005), "The Intimacy of State Power: Marriage, Liberation, and Socialist Subjects in Southeastern China", American Ethnologist 32(2): 312327.

Greenhalgh, Susan and Edwin A. Winckler (2005), Governing China's Population: From Leninist to Neoliberal Biopolitics, Stanford: Stanford University Press. Hershatter, Gail (1984), "Making a Friend: Changing Patterns of Courtship in Urban China", Pacific Affairs 57(2): 237-251.

Hochschild, Arlie (1989), The Second Shift: Working Parents and the Revolution at Home, New York: Viking.

Honig, E. and G. Hershatter (1988), Personal Voices: Chinese Women in the 1980's, Stanford: Stanford University Press.

Hong-Fincher, Leta (2012), “Weihe Zhongguo Fulian dui 'shengnü' weiyansongting" (Why is the ACWF alarmist over leftover women?), The New York Times, October 15, available at: https://cn.nytimes.com/opinion /20121015/c15fincher/ (accessed 03.06.2017).

Hong-Fincher, Leta (2014), Leftover Women: The Resurgence of Gender Inequality in China, London: Zed Books. 
-- (2018), Betraying Big Brother: The Feminist Awakening in China, New York: Verso Books.

Hooper, B. (1998), "'Flower Vase and Housewife': Women and Consumerism in Post-Mao China", 167-193, in K. Sen and M. Stivens (eds.), Gender and Power in Affluent Asia, London: Routledge.

Huang, Hongru and Xin Huanyu (2016), "Gaoxiao, gongli yiyuan quxiao shiye danwei bianzhi, qianwan ren jiang diu tiefanwan" (Universities and public hospitals terminate permanent posts, thousands of millions will lose their iron rice bowl?), Xinhua wang, August 9, available at: http://www.xinhuanet.com/yuqing/2016-08/09/c_129215738.htm (Accessed 23.10.2018).

Jackson, Stevi, Petula Sik Ying Ho and Jin Nye Na (2016), "Interviewing Across Cultures: Talking to Mothers and Daughters in Hong Kong and Britain", 3043, in Gabriele Griffin (ed.), Cross-Cultural Interviewing: Feminist Experiences and Reflections, Oxon: Routledge.

Journeyman Pictures (2012), "China's Female Millionaires are in a Matchmaking Frenzy", available at: https://www.youtube.com/watch?v=NGTfjtyVUCw (accessed 12.07.2017).

Li, Xuan (2017), “Pity China's 'Bare Branches': Unmarried Men Stuck Between Tradition and Capitalism", The Conversation, available at: http://theconversati on.com/pity-chinas-bare-branches-unmarried-menstuck-between-tradition-a nd-capitalism-68592 (31.01.2018).

Li, Zhiyan and Liu Huizhen (2015),“Gaoxiao jiaoshi pinren zhidu de zhengce daoxiang yu lilun jichu wenti fenxi" (Analysis of the principles and problems of university lectureship employment policies), Zhongguo jiaoyu xinwenwang, available at: http://www.jyb.cn/theory/lltw/201512/t20151 223_647619.html (accessed 05.11.2018).

Liu, Jieyu (2008), "Sexualized Labour? 'White-Collar Beauties' in Provincial China", 85-103, in S. Jackson, J. Liu and W. Juhyun (eds.), East Asian Sexualities: Modernity, Gender \& New Sexual Cultures, London: Zed Books. - - (2017), Gender, Sexuality and Power in Chinese Companies: Beauties at Work, London: Palgrave.

McMillan, Joanna (2006), Sex, Science and Morality in China, London: Routledge. Peng, X. (2011), "China's Demographic History and Future Challenges", Science 333(6042): 581-587. 
Poston, Dudley L. and Karen S. Glover (2005), "Too Many Males: Marriage Market Implications of Gender Imbalances in China", Genus 61(2): 119-140. PRC Population Bureau (2010), Tabulation on the 2010 Population Census of the People's Republic of China, available at: http://www.stats.gov.cn/tjsj/p csj/rkpc/6rp/indexch.htm (accessed 01.12.2018).

Qi, Xiaoying (2014), "Filial Obligation in Contemporary China: Evolution of the Culture-System", Journal for the Theory of Social Behaviour 45(1): 141-161.

Reay, Diane (2014), "From Academic Freedom to Academic Capitalism", Discover Society, available at: http://discoversociety.org/2014/02/15/onthe-frontline-from-academic-freedom-to-academic-capitalism/ (accessed 08.08.2017).

Res-Sisters (2017), "I'm an Early Career Feminist Academic: Get Me Out of Here? Encountering and Resisting the Neoliberal Academy", 267-284, in R. Thwaites and A. Pressland (eds.), Being an Early Career Feminist Academic: Global Perspectives, Experiences and Challenges, London: Springer.

Riskin, Carl, Zhaohui Renwei and Li Shih (2001), China's Retreat from Equality: Income Distribution and Economic Transition, New York: M.E. Sharpe.

Robinson, J.C. (1985), "Of Women and Washing Machines: Employment, Housework, and the Reproduction of Motherhood in Socialist China", The China Quarterly, 101: 32-57.

Rubin, Herbert J. and Irene S. Rubin (2012), Qualitative Interviewing: The Art of Hearing Data, London: Sage.

Sigley, Gary (2001) "Keep it in the Family: Government, Marriage, and Sex in Contemporary China", 118-153, in J. Margret and R. Kalpana (eds.), Borders of Being: Citizenship, Fertility, and Sexuality in Asia and the Pacific, Ann Arbor: The University of Michigan Press.

Sohu News (2018), "2018 daxue xingbie bili baogao mei xiangdao shi zheyang" (2018 university graduate gender ratio report, surprise!), April 5, available at: www.sohu.com/a/227342403_391394 (accessed 28.10.2018).

Sun, Shengwei and Chen Feinian (2015), "Reprivatized Womanhood: Changes in Mainstream Media's Framing of Urban Women's Issues in China, 19952012", Journal of Marriage and Family 77(5): 1091-1107.

The World Bank (2016), "Labor Force Participation Rate, Female (\% of Female Population Ages 15+)", available at: http://data.worldbank.org/indicator/S L.TLF.CACT.FE.ZS?page=3 (accessed 01.08.2017). 
To, Sandy (2013), “Understanding Sheng Nu (Leftover Women): The Phenomenon of Late Marriage Among Chinese Professional Women", Symbolic Interaction 36(1): 1-20.

Tsui, Ming and Lynne Rich (2002), "The Only Child and EducationalOpportunity for Girls in Urban China", Gender and Society 16(1): 74-92.

Wang, Feng (2010), "China's Population Destiny: The Looming Crisis”, Brookings, September 30, available at: https://www.brookings.edu/articles/chinaspopulation-destiny-the-looming-crisis/ (accessed 01.07.2017).

Wolf, Margery (1985), Revolution Postponed: Women in Contemporary China, Stanford: Stanford University Press.

Wong, Day (2016), "Sexology and the Making of Sexual Subjects in Contemporary China", Journal of Sociology 52(1): 68-82.

Wu, Xiaoying (2010), "From State Dominance to Market Orientation: The Composition and Evolution of Gender Discourse", Social Sciences in China 31(2): 150-164.

Xie, Kailing (2017), “'Her China Dream': The Aspirations of China's Privileged Daughters", DiscoverSociety 48, September 5, available at: https://discoversociety.org/2017/09/05/her-china-dream-the-aspirationsof-chinas-privileged-daughters/ (accessed 06.11.2018).

- - (2018), "Premarital Abortion-What is the Harm? The Responsibilisation of Women's Pregnancy Among China's 'Privileged' Daughters", Journal of the British Association for Chinese Studies, 8(2): 1-31.

Yang, Hui (2012), “Urban Women's Gender Discrimination Issues in Employment", Women of China, September 6, available at: http://www.womenofchina.cn/html/womenofchina/report/144652-1.htm (accessed 27.07.2017).

Yang, Nini, Chao C. Chen, Jaepil Choi and Yimin Zou (2000), "Sources of WorkFamily Conflict: A Sino-US Comparison of the Effects of Work and Family Demands", Academy of Management Journal 43(1): 113-123.

Zeng, Jennifer and Michael Thorneman (2014), "Advancing Gender Parity in China: Solutions to Help Women's Ambitions Overcome the Obstacles", Insights, November 26, available at: http://www.bain.com/pu blications/articles/advancing-gender-parity-in-china.aspx (accessed 07.08. 2017).

Zhihu (2013), "Daxue laoshi yueshouru shifou zhi you san dao wu qian? Ruguo shi, weishenme bu tiaocao?"(University teachers' monthly income only 
three to five thousand yuan? If so, why not quit?), Zhihu, available at: https://www.zhihu.com/question/20362737 (accessed 23.10.2018).

Zhou, Viola (2017), "Marriage Rate Down, Divorce Rate Up as More Chinese Couples Say "I Don't' or 'I Won't Any More", available at: https://www.scmp.com/news/china/society/article/2109868/marriage-ra te-down-divorce-rate-more-chinese-couples-say-i-dont (accessed 02. 12.2018].

Zurndorfer, Harriet (2016), "Men, Women, Money, and Morality: The Development of China's Sexual Economy", Feminist Economics 22(2): 1-23. Zheng, Xiangyu (2018), “'Zhuanjia tan' jinxiao dao, zheng jiafeng” (Expert talk on filial piety, family value), Zhongqin zaixian, March 3, available at: http://news.cyol.com/yuanchuang/2018-03/03/content_16987726.htm (accessed 29.11.2018)

Kailing Xie is a Teaching Fellow in the Department of Politics and International Studies at the University of Warwick. 